\title{
Promoção de saúde oral em indivíduos com microcefalia: Relato de experiência
}

\author{
Gabriella Souza Santos Félix ${ }^{1}$, Maria da Conceição Andrade de Freitas ${ }^{2}$, Taylline das Mercês \\ Gonçalves³, Dara Vitória Pereira Lopes Silva4, Fernanda de Carvalho Reis5, Felipe Barros Castro6, \\ Mayana Narde Souza7, Matheus Soledade Carvalho Santos ${ }^{8}$
}

Resumo: Um aumento significativo de recém-nascidos com microcefalia ocorreu desde 2015 no Brasil. Este relato descreve ações extensionistas desenvolvidas pelos discentes do curso de Odontologia de uma universidade pública brasileira. De 2017 a 2019, efetuaramse ações de prevenção de doenças e promoção de saúde bucal, acompanhamento do desenvolvimento dentário/craniofacial e tratamento odontológico em indivíduos com Microcefalia. Foram atendidas 17 crianças e 2 adolescentes. Referente a hábitos alimentares e higiene oral, observou-se dieta pastosa e noturna, ausência de escovação da língua e a dentária, apenas uma vez por dia. Na análise facial, desarmonia e comprometimento funcional orofacial. No exame intraoral, observou-se biofilme visível, interposição lingual anterior atípica, mastigação unilateral, bruxismo dentário e desenvolvimento dentário normal. Realizaram-se abordagens educativas de higiene oral aos familiares, atenciosos ao aprendizado. $\mathrm{O}$ atendimento odontológico ocorreu de acordo com as necessidades de risco de cárie, desgastes dentários e doença periodontal. Houve a promoção do conhecimento científico e os benefícios advindos do ensino, pesquisa e extensão destas ações proporcionaram um elo entre a comunidade acadêmica e a sociedade.

Palavras-chave: Assistência Odontológica; Pessoas com Deficiências; Saúde Pública; Odontologia

\section{Promotion of oral health in individuals with microcephaly: Experience report}

Abstract: A significant increase in newborns with microcephaly has occurred since 2015 in Brazil. This report describes extension actions developed by students of the Dentistry course at a Brazilian public university. From 2017 to 2019, actions for preventing oral diseases, monitoring dental/craniofacial development, and dental treatment were made available to individuals with microcephaly by students of the Dentistry course at UESB. Seventeen children and two teenagers were attended. A pasty and nocturnal diet, absence of tongue, and dental brushing were observed only once a day regarding eating habits and oral hygiene. In facial analysis, disharmony and orofacial functional impairment. Visible biofilm, atypical anterior lingual interposition, unilateral chewing, dental bruxism, and normal tooth development were observed in the intraoral examination. Educational approaches on oral hygiene were carried out to family members, attentive to learning. The dental care was following the needs of risk of caries, dental wear, and periodontal disease. Scientific knowledge was promoted. The benefits arising from teaching, research, and the extension regarding these actions link the academic community and society.

Keywords: Dental Care; People with disabilities; Public Health; Dentistry
Originais recebidos em

25 de março de 2021

Aceito para publicação em

8 de setembro de 2021

1

Graduanda em Odontologia (UESB)

https://orcid.org/0000-0003-3953-7115

(autora para correspondência)

gabriellasouza.gg7@gmail.com

2

Doutora em Ciências da Reabilitação pela USP, docente em Odontologia da Universidade Estadual do Sudoeste da Bahia (UESB)

http://orcid.org/0000-0002-9320-9588 3

Graduanda em Odontologia (UESB) https://orcid.org/0000-0002-8973-905X 4

Graduanda em Odontologia (UESB) https://orcid.org/0000-0001-8660-833X 5

Graduanda em Odontologia (UESB) https://orcid.org/0000-0003-3566-8337 6 Graduanda em Odontologia (UESB) https://orcid.org/0000-0003-2698-1639 7

Graduando em Odontologia (UESB) https://orcid.org/0000-0002-3817-9144 8

Graduando em Odontologia (UESB) https://orcid.org/0000-0001-9305-024X 


\section{Introdução}

As crianças com microcefalia, comunidade pela qual o projeto atende, apresentam uma redução significativa do perímetro cefálico occipitofrontal em comparação com outras do mesmo sexo e idade. Além da desproporção craniofacial, essa condição pode acarretar malformações articulares dos membros, alterações no crescimento e desenvolvimento neuropsicomotor, bem como dificuldades auditivas e visuais (Devakumar et al., 2018; França et al., 2018; Carvalho-Sauer et al., 2020). Em virtude do estado de emergência pública nacional, o Ministério da Saúde do Brasil adotou, em 2016, definições operacionais com base na medida do perímetro cefálico (PC) em conformidade com a Organização Mundial de Saúde (OMS), a qual instituiu uma referência normativa, para as primeiras $24-48 \mathrm{~h}$ de vida, pelos parâmetros InterGrowth para ambos os sexos. Nesta nova tabela de referência do PC, a medida para o recém-nascido (RN) a termo é de $31,5 \mathrm{~cm}$ para meninas e 31,9 cm para meninos. A OMS padroniza como Microcefalia: RN com um PC inferior a -2 desvios-padrão (DP) e microcefalia grave: RN com um perímetro cefálico inferior a -3 DP para idade gestacional e sexo (World Health Organization [WHO], 2016; Ministério da Saúde, 2017).

O aumento significativo de recém-nascidos com Microcefalia nas regiões norte e nordeste do Brasil, vislumbrou a implantação de diretrizes governamentais nas unidades de atenção básica e especializada de saúde que englobe o diagnóstico, intervenção precoce e atenção contínua por uma equipe de saúde interdisciplinar para esta população vulnerável (Ministério da Saúde, 2016). Destarte, é notória a importância da reabilitação para estes indivíduos, ressaltando também a necessidade da inclusão de diretrizes relacionadas ao diagnóstico e tratamento bucomaxilofacial. A atenção à saúde oral engloba o desenvolvimento dentário, o sistema estomatognático e o crescimento craniofacial na primeira infância a fim de reduzir significativamente medidas curativas. Mas, como ficaria este acesso aos indivíduos com microcefalia? Esta má formação congênita pode interferir no desenvolvimento dentário e no crescimento craniofacial? Em qual magnitude as funções orofaciais vão se expressar? A literatura revisada demonstra a ocorrência de alterações na cronologia e sequência de erupção dentária, opacidade do esmalte dos dentes decíduos, bem como alterações na tonicidade muscular facial, respiração e deglutição em crianças na primeira infância diagnosticadas com microcefalia ao nascer a termo, sem associação a síndromes (Gomes, 2019; D'Agostino et al., 2020; Faria et al., 2020; Ribeiro et al., 2020).

Em 2002, a Organização Mundial da Saúde, referência internacional na área de anomalias craniofaciais, publicou o documento intitulado Global Strategies to reduce the Health-Care Burden of Craniofacial Anomalies com diretrizes de protocolo de atenção à esta população englobando à saúde oral (WHO, 2002). Neste contexto, a relevância do presente trabalho consiste no seu caráter ímpar na promoção da saúde oral em indivíduos com microcefalia ao objetivar descrever as ações extensionistas desenvolvidas pelos discentes do curso de Odontologia da Universidade Estadual da Bahia no projeto de extensão intitulado Centro Odontológico Álvaro Marques - Microcefalia.

\section{Material e Métodos}

O presente estudo possui uma abordagem qualitativa de caráter descritivo, do tipo relato de experiência das atividades desenvolvidas do projeto intitulado Centro Odontológico Álvaro Marques-Microcefalia, que teve início em abril de 2017 com término em dezembro de 2019. Este projeto possui a participação de discentes da graduação e docentes do curso de Odontologia da Universidade Estadual do Sudoeste da Bahia (UESB). As ações extensionistas têm caráter interdisciplinar com participação de diversas especialidades da Odontologia como Odontopediatria, Periodontia, Cirurgia Bucomaxilofacial, Endodontia, Dentística e Odontologia para 
pacientes com necessidades especiais. O caráter interinstitucional deste projeto se reflete na colaboração da docente do curso de Fonoaudiologia da Universidade Estadual da Bahia (UNEB).

O público atendido contempla os indivíduos com microcefalia nascidos em Jequié-Bahia e cidades vizinhas e seus respectivos responsáveis e familiares. As ações de extensão tiveram como objetivos: 1) Promoção da Saúde Bucal através de diagnóstico bucal, tratamento odontológico e análise do padrão funcional da musculatura orofacial. 2) Socialização do conhecimento científico com a comunidade acadêmica 3) Visitas a instituições governamentais e não governamentais que atendem a esta população vulnerável. As atividades de atendimento odontológico e análise fonoaudiológica são realizadas no Módulo de Odontologia da UESB com carga horária de 16 horas/mês. As ações científicas basearam-se na história clínica, que continha as condições socioeconômicas e demográficas da população estudada, história neonatal, fatores comportamentais relacionados à alimentação e saúde bucal, análise dos padrões faciais e orofuncionais, condição dentária e periodontal, bem como tratamento dos indivíduos com microcefalia, sendo realizados nas salas de aula ou auditório da UESB, com carga horária de 08 horas/mês.

A divulgação deste projeto é feita por meio digital através de publicações no site da Universidade, envios semanais de vídeos lúdicos e explicativos por meio do Whatsapp sobre os cuidados em saúde bucal nas crianças com microcefalia, nos quais os cuidadores ou responsáveis foram devidamente instruídos, buscando promoção da saúde oral e orientação acerca do desenvolvimento dentário e da higienização oral, utilizando do método de escuta ativa. Além disso, foi realizado o compartilhamento de folhetos informativos direcionados às comunidades interna e externa da UESB, instituições governamentais como NUPREJ (Núcleo de Prevenção e Reabilitação Física de Jequié) e não governamentais como APAE (Associação de Pais e Amigos dos Excepcionais), além de centros comunitários que assistem indivíduos com microcefalia nascidos em JequiéBahia e seus cuidadores, de modo a realizar a captação do público, tanto para desempenhar ações iniciais de prevenção como para ofertar atendimento odontológico. O projeto também é propagado por intermédio das produções de trabalhos para apresentação na comunidade científica.

A avaliação deste projeto consiste numa análise qualitativa dos depoimentos e relatórios dos três públicos: a população assistida; os discentes voluntários e bolsistas; os docentes.

\section{Relato de experiência e Discussão}

De abril de 2017 a dezembro de 2019, foram realizadas ações extensionistas do projeto "Centro Odontológico Álvaro Marques- Microcefalia" no Módulo de Odontologia da UESB às terças-feiras pela manhã pelos docentes e discentes voluntários e bolsistas do curso de Odontologia da UESB, totalizando 22 discentes voluntários e 6 bolsistas, bem como 7 docentes colaboradores das diversas especialidades da Odontologia como Odontopediatria, Periodontia, Cirurgia Bucomaxilofacial, Endodontia, Dentística e Odontologia para pacientes com necessidades especiais. Houve também a colaboração da docente do curso de Fonoaudiologia da UNEB responsável pela análise da mastigação e do padrão da musculatura orofacial dos indivíduos com microcefalia e realização de palestra para comunidade acadêmica.

Inicialmente foram realizadas promoções de saúde oral pelos docentes e discentes participantes deste projeto para os indivíduos com microcefalia e seus respectivos familiares e/ou responsáveis, nas Associações de Pais e Amigos dos Excepcionais de Jequié, Porto Seguro e Eunápolis e o Núcleo de Prevenção e Reabilitação Física de Jequié, Bahia, Brasil. Esta ação consistiu em orientações sobre a importância da saúde oral, indicação e doações de escovas, dentifrícios e fios dentais, bem como o ensino da técnica de higienização dos dentes e da língua, a fim de promover a saúde bucal à toda família. Três palestras educativas foram realizadas para as crianças e seus familiares sobre saúde da boca, contemplando 28 famílias. Esta ação desenvolvida teve um impacto positivo pelo empoderamento desta população vulnerável a respeito da adoção de medidas de 
prevenção e higienização oral, explicando conceitos ainda inexistentes sobre este assunto. É importante salientar os depoimentos favoráveis dos pais e/ou responsáveis destas crianças referentes à orientação da estimulação contínua da criança na empunhadura da escova dentária com a tentativa de escovar os dentes na rotina, três vezes ao dia (Figura 1 ). Esta atividade proporcionou, nos relatos dos 28 discentes participantes, a oportunidade de uma formação diferenciada, voltada à prática humanizada no serviço de saúde.

As ações extensionistas referentes ao atendimento e tratamento odontológico e da análise fonoaudiológica foram realizadas no Módulo de Odontologia da UESB. Foram atendidos no total 19 indivíduos, sendo 2 adolescentes, de 15 e 18 anos de idade, 17 crianças, entre 3 a 9 anos de idade, em que 13 apresentavam dentição decídua e 4 apresentavam dentição mista. Em avaliação clínica odontológica, registrou-se a partir do histórico médico que todos os indivíduos atendidos tinham diagnóstico de microcefalia ao nascer a termo, com comprometimento neuropsicomotor, alterações auditivas e visuais. Dois pacientes apresentaram malformações nos dedos das mãos e pés. Um paciente possuía Síndrome Cri-du-Chat. Todos os pais/responsáveis pelos pacientes atendidos relataram que os mesmos possuíam dieta pastosa com ingestão noturna, além de apresentarem o hábito de ressonar. Não faziam sucção de dedo ou chupeta. Com relação à higiene oral, observou-se escovação dentária uma vez por dia e ausência de escovação da língua. Na análise facial, verificou-se desarmonia na relação sagital das bases apicais e ausência de selamento labial passivo com rotação da mandíbula no sentido horário, sugestivo de crescimento no sentido vertical. No exame intraoral, observou-se salivação em abundância, interposição lingual anterior atípica, biofilme visível, bruxismo dentário e desenvolvimento dentário normal.

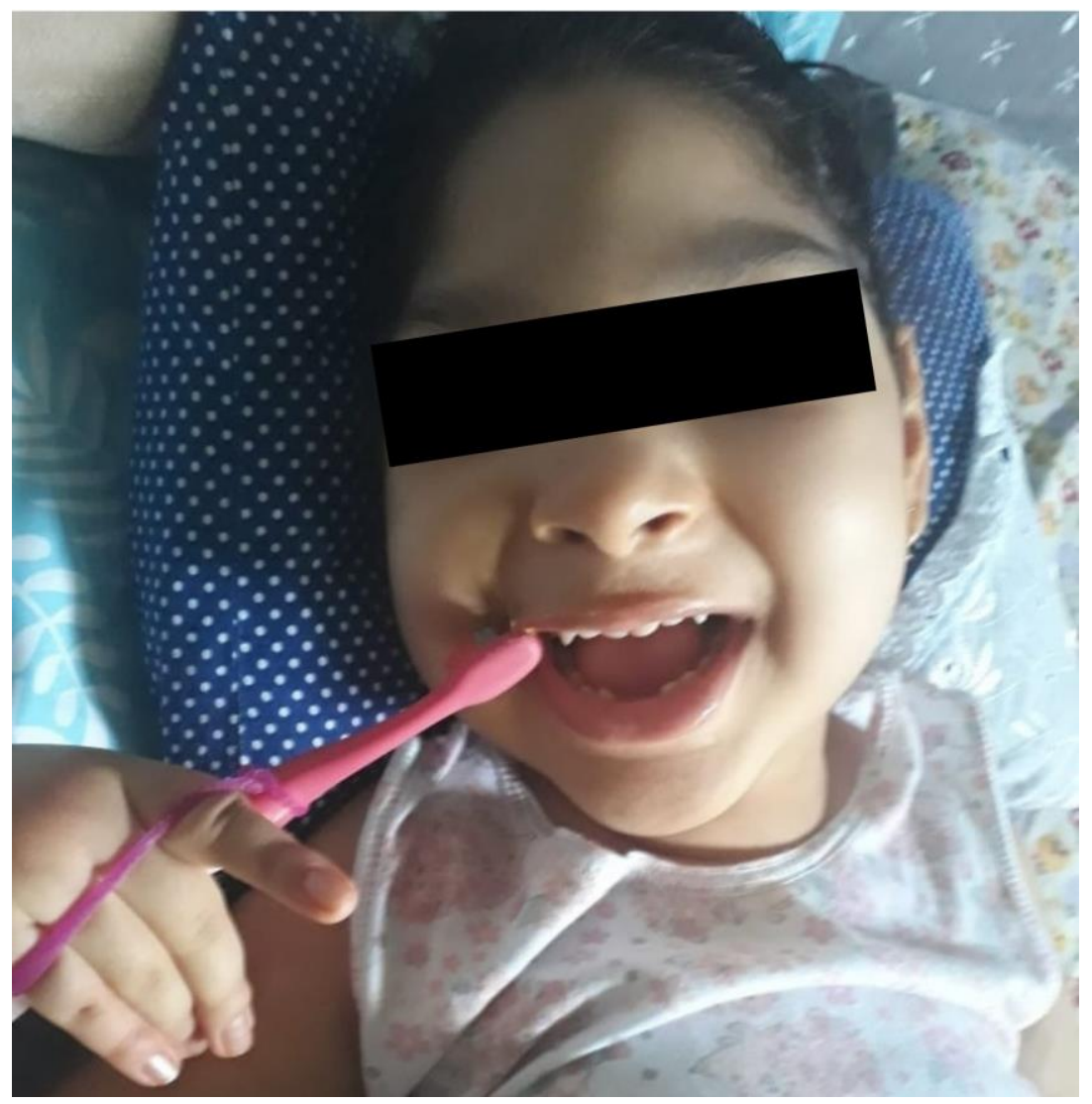

Figura 1. Paciente com microcefalia, 5 anos de idade, em higienização oral em ambiente domiciliar, conforme orientação recomendada pela equipe do projeto extensionista à mãe da paciente para promoção da saúde oral e estímulo precoce do córtex cerebral. 
O atendimento odontológico ocorreu de acordo com as necessidades de risco de cárie, desgastes dentários e doença periodontal. A maior demanda para reabilitação oral ocorreu nos dois pacientes adolescentes (Figura 2). Para possibilitar o exame e o procedimento odontológico foram utilizadas as seguintes técnicas de condicionamento: controle de voz, distração, estabilização protetora com contenção física do pescoço, mãos e pés feita pelo responsável e discentes participantes, assim como o uso de abridor de boca unilateral no tratamento do lado contralateral (Figura 3). Durante todo acompanhamento/tratamento odontológico foi distribuído um kit de higiene bucal e realizada a orientação e estímulo sobre higienização oral. Na maioria dos casos, os responsáveis costumavam relatar que o paciente nem escovava os dentes e nem permitia que ninguém o fizesse na sua rotina diária, o que acarretava um comprometimento do convívio social pelo mau hálito provocado na fala e pelo odor deixado nos lençóis quando dormiam e salivavam. Diversas barreiras foram quebradas, desde a higienização, que foi permitida realizar, como tratamentos no ambiente odontológico, anteriormente impensáveis pelos pais. Os discentes participantes perceberam a importância da ação de inclusão no desenvolvimento de atividades odontológicas e a divulgação da ciência numa linguagem mais acessível para esta população vulnerável. A percepção do aluno neste estudo sobre a trajetória extensionista segue a reflexão de Pietrovski e cols. (2018), que desvincula as ações de extensão de um caráter assistencialista, com ampliação no âmbito profissional e social.

A análise do padrão funcional da musculatura orofacial foi realizada pela terapêutica interdisciplinar com a fonoaudiologia. Consistiu no exame clínico e análise das imagens de vídeos da mastigação, deglutição e musculatura orofacial dos pacientes atendidos pela docente colaboradora do curso de Fonoaudiologia da UNEB. Todos os pacientes apresentaram mastigação unilateral, deglutição atípica e interposição lingual atípica, corroborando com os achados miofuncionais em criança com microcefalia relatados por Faria e colaboradores (2020), que constataram modificações do padrão dos reflexos orais. Como os pacientes já eram acompanhados por seus respectivos fonoaudiólogos, foi feito um relatório sobre as alterações observadas e solicitação de fonoterapia. Houve um comprometimento destes profissionais para adequação miofuncional destes pacientes. Em 2019, observou-se durante o acompanhamento odontológico destes pacientes a melhora nas funções orais. Pelas observações dos cuidadores destes pacientes, houve a promoção do bem estar físico e social. Quanto aos discentes envolvidos neste projeto, relataram contribuição importante desta prática interdisciplinar no serviço de saúde para suas formações pedagógicas.

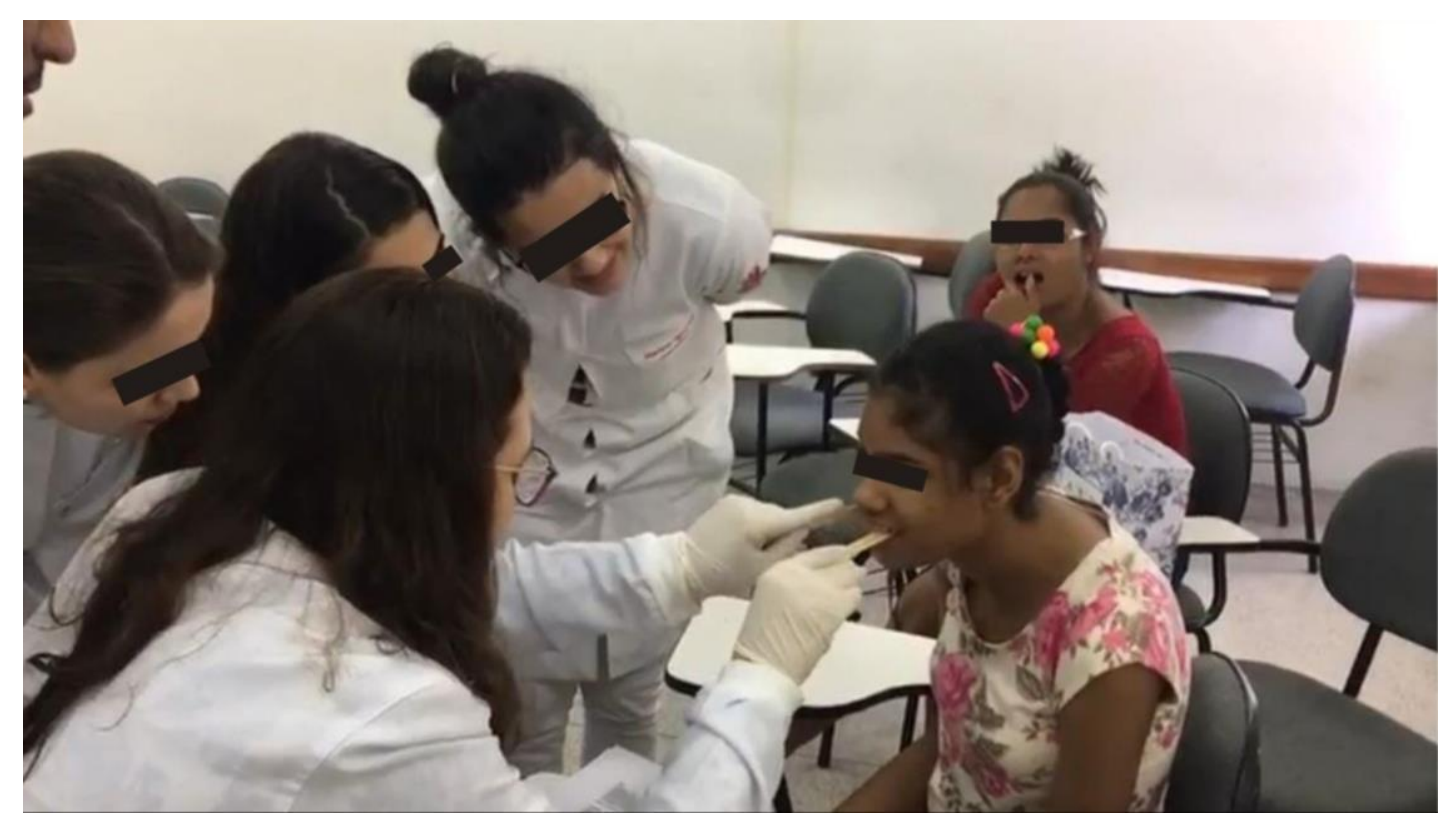

Figura 2. Atendimento fonoaudiológico em uma adolescente com microcefalia. 
Figura 3. Atendimento odontológico em criança com microcefalia no colo da mãe, sem necessidade de uso de equipamentos imobilizadores.

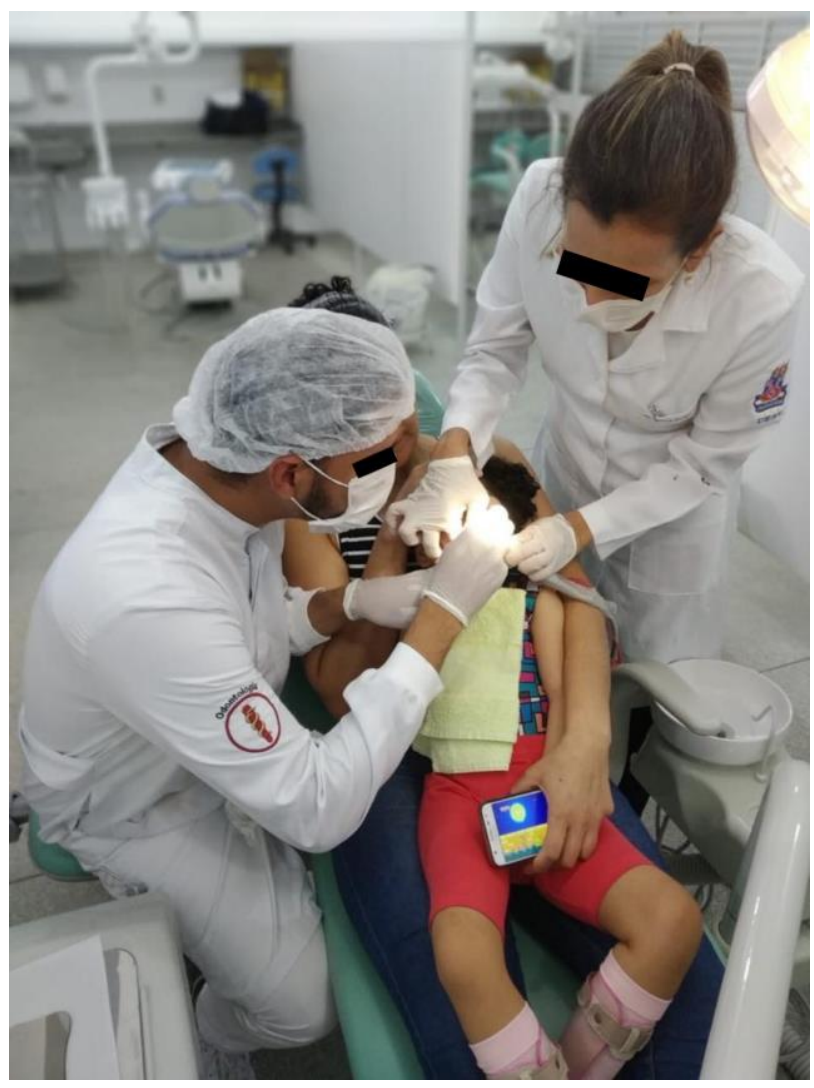

A socialização do conhecimento científico com a comunidade acadêmica consistiu em reuniões pedagógicas duas vezes/mês e apresentação de seminários dos casos clínicos em atendimento uma vez/mês pelos discentes voluntários e bolsistas. Os alunos bolsistas deste projeto apresentaram seminários sobre Microcefalia para os da graduação da disciplina de Patologia Bucodental do curso de Odontologia da UESB no semestre curricular vigente. Foram ministradas as palestras "Analgesia inalatória na Odontologia" e "Odontologia e Fonoaudiologia dialogando no cuidado dos indivíduos com anomalias craniofaciais" por profissionais convidados de outras instituições de ensino superior no auditório da UESB, em 2018 e 2019, totalizando 42 e 51 ouvintes inscritos, respectivamente. A elaboração de produção científica sobre este projeto resultou em 3 aprovações de trabalhos (painel científico/apresentações orais) em eventos científicos nacionais. Dentre eles, uma premiação em primeiro lugar na modalidade de extensão.

As dificuldades encontradas durante a execução deste projeto, como ausência de materiais odontológicos para realização de procedimentos, locomoção dos pacientes e seus responsáveis, problemas estruturais do ambiente odontológico, entre outros, foram superadas gradativamente, contribuindo com a aprendizagem para projetos futuros. Em função ao comprometimento neurológico das crianças atendidas, não foi possível a realização de radiografias para auxiliar no diagnóstico e reabilitação oral. Em relação aos pacientes adolescentes, este problema foi resolvido após a familiarização com o ambiente odontológico.

Os impactos positivos na comunidade atendida durante todo o período do projeto foram observados pelos relatos dos cuidadores da melhora da saúde oral desta população vulnerável, refletindo na sua socialização, e pela assiduidade aos atendimentos, mesmo com a dificuldade financeira e de mobilidade urbana. Nos relatórios dos discentes, as ações extensionistas teóricas e práticas desenvolvidas corroboraram significativamente para o enriquecimento dos seus currículos acadêmicos, relacionando à teoria e a prática com a habilidade de ação transformadora no seu futuro profissional. Em relação aos docentes, potencializou 
a importância da execução do elo ensino, pesquisa e extensão. O impacto negativo ocorreu frente às adversidades da vida. Em abril de 2019 houve a comunicação a coordenadora deste projeto sobre o falecimento de uma das pacientes com 4 anos de idade, por complicações respiratórias.

\section{Conclusão}

A maioria dos resultados deste trabalho foram observados a longo prazo, mas, como observação imediata, foi possível verificar a carência dos pacientes assistidos em relação ao tratamento odontológico, a descrença dos responsáveis em relação à colaboração do filho quanto à prevenção oral e atendimento odontológico. No entanto, o que foi visto foi o medo e resistência inicial, facilmente quebrados com a abordagem adequada, o acompanhamento lúdico, a explicação, a técnica de "dizer, mostrar e fazer" e o cuidado com o paciente. É imprescindível a adoção de medidas preventivas e interceptativas no âmbito da saúde pública nos indivíduos com microcefalia para definição de um prognóstico realista e elaboração de um protocolo de atenção à saúde. Os benefícios advindos do ensino, pesquisa e extensão destas ações proporcionaram um elo permanente entre a comunidade acadêmica e a sociedade.

\section{Contribuições de cada autor}

Todos os autores contribuíram para a elaboração e execução das atividades extensionistas deste projeto; M.C.A.F. planejou o projeto, atuou como coordenador e orientador dos bolsistas e voluntários; T.G. e D.S. revisão bibliográfica; M.C.A.F., M.S., e F.C. foram responsáveis pela análise dos depoimentos dos responsáveis e relatórios dos discentes; G.F. e M.C.A.F. escreveram o artigo; F.R. e M.S. validaram os achados e impactos gerados; G.F. submissão do artigo à revista; Todos os autores revisaram criticamente o manuscrito e ajudaram na preparação do artigo.

\section{Referências}

Carvalho-Sauer, R. C. O., Costa, M. D. C. N., Paixão, E. S., de Jesus Silva, N., Barreto, F. R., \& Teixeira, M. G. (2020). Crosssectional study of the anthropometric characteristics of children with congenital Zika syndrome up to 12 months of life. BMC Pediatrics, 20(1): 1-9.

Devakumar, D., Bamford, A., Ferreira, M. U., Broad, J., Rosch, R. E., Groce, N., ... \& Abubakar I. (2018). Infectious causes of microcephaly: epidemiology, pathogenesis, diagnosis, and management. Lancet Infectious Diseases, 18(1): e1-e13.

D’Agostino, É. S., Chagas, J. R. L. P., Cangussu, M. C. T., \& Vianna, M. I. P. (2020). Chronology and sequence of deciduous teeth eruption in children with microcephaly associated to the Zika virus. Special Care in Dentistry, 4(1): 3-9.

França, T. L. B., Medeiros, W. R., Souza, N. L., Longo, E., Pereira, S. A., França, T. B. O., \& Sousa, K. G. (2018). Growth and development of children with microcephaly associated with congenital Zika virus syndrome in Brazil. International Journal of Environmental Research and Public Health, 15(9): 1990.

Faria, J. K. C., Feitosa, A. L. F., \& Canuto, M. S. B. C. (2020). Achados miofuncionais orofaciais em crianças com microcefalia. Distúrbios da Comunicação, 32(3): 462-469.

Gomes, P. N. (2019). Alterações dentárias em crianças com microcefalia associada à Síndrome Congênita do Zika Vírus e outras infecções congênitas (Tese de Doutorado). Universidade Federal do Rio Grande do Norte, Natal, Brasil. Recuperado de https://repositorio.ufrn.br/handle/123456789/28639

Ministério da Saúde. (2016). Diretrizes de estimulação precoce. Crianças de zero a 3 anos com atraso no desenvolvimento neuropsicomotor decorrente de microcefalia. Brasília: Ministério da Saúde. Recuperado de https://bvsms.saude.gov.br/ bvs/publicacoes/diretrizes estimulacao criancas 0a3anos neuropsicomotor.pdf 
Ministério da Saúde. (2017). Orientações integradas de vigilância e atenção à saúde no âmbito da Emergência de Saúde Pública de Importância Nacional: Procedimentos para o monitoramento das alterações no crescimento e desenvolvimento a partir da gestação até a primeira infância, relacionadas à infecção pelo vírus Zika e outras etiologias infecciosas dentro da capacidade operacional do SUS. Ministério da Saúde, Secretaria de Vigilância em Saúde, Secretaria de Atenção à Saúde. Brasília: Ministério da Saúde. Recuperado de https://bvsms.saude.gov.br/bvs/publicacoes/ orientacoes integradas vigilancia atencao emergencia saude publica.pdf

Pietrovski, E. F., Bronzeri, M. S., Cunha, J. C., Reis, D. R., \& Alegre, L. M. P. (2018). A prática extensionista em uma universidade pública federal. Extensio: Revista Eletrônica de Extensão, 15(29): 2-19.

Ribeiro, R. A., Mattos, A., Meneghim, M. C., Vedovello, S. A. S., Borges, T. M. D., \& Santamaria, M. (2020). Oral and maxillofacial outcomes in children with microcephaly associated with the congenital Zika syndrome. European Journal of Orthodontics, 43(3), 346-352.

World Health Organization. (2002). Global strategies to reduce the health: Care burden of craniofacial anomalies. Geneva: WHO.

World Health Organization. (2016). Assessment of infants with microcephaly in the context of Zika virus - Interim Guidance, Geneva: WHO.

Como citar este artigo:

Félix, G. S. S., Freitas, M. da C. A. de, Gonçalves, T. das M., Silva, D. V. P. L., Reis, F. de C., Castro, F. B., Souza, M. N., \& Santos, M. S. S. (2021). Promoção de saúde oral em indivíduos com microcefalia: Relato de experiência. Revista Brasileira de Extensão Universitária, 12(3), 321-328. https://periodicos.uffs.edu.br/index.php/RBEU/article/view/ $\underline{12208 / \mathrm{pdf}}$ 